\title{
Combined use of extracorporeal carbon dioxide removal (ECCO2-R) and Noninvasive Mechanical Ventilation in hypercapnic acute respiratory failure due to COPD exacerbations in patients at risk of NIMV failure: a rationale of use
}

\author{
Longobardi S,' Bocchino V, ${ }^{2}$ Squillante $F^{3}$ Mazzarella $G^{4}$, Schettini $C^{\prime}$ \\ 'Azienda Ospedaliero-Universitaria Regionale San Carlo, Potenza \\ ${ }^{2}$ Respiratory Intermediate-Intensive Care Unit,Azienda Ospedaliera Monaldi, Italy \\ ${ }^{3}$ Respiratory Intermediate-Intensive Care Unit, Azienda Ospedaliera Monaldi, Italy \\ ${ }^{4}$ Second University of Naples, Cardiothoracic and Respiratory Sciences, Italy
}

Correspondence: Longobardi S, Respiratory Fisiophatology and Pulmonary Critical Care Unit,Azienda Ospedaliero Universitaria Regionale “San Carlo”, Potenza, Italy, Tel 00393493683 I23, Email salvatoredlongobardi@gmail.com

Received: January 31, 2018 | Published: February 19, 2018

Copyright@ 2018 Longobardi et al. This is an open access article distributed under the terms of the Creative Commons Attribution License, which permits unrestricted use, distribution, and reproduction in any medium, provided the original author and source are credited.

\section{Introduction}

Acute respiratory failure in patients with Chronic Obstructive Pulmonary Disease (COPD) is characterized by high levels of hypercapnia. To date, state-of-art treatment includes mechanical ventilation support. Our study was designed from a matched cohort study with historical control conducted by Chandra et al, Del Sorbo et al. ${ }^{1,2}$ in 2014 that provided the rationale to use ECCO2-R in hypercapnic respiratory failure and respiratory acidosis non responsive at NIV at risk of endotracheal intubation (E.T.I).

\section{Aim}

The aims of this study are to evaluate the effectiveness of noninvasive ventilation and extracorporeal carbon dioxide removal in hypercapnic respiratory failure with respiratory acidosis in COPD patients, and to prevent endotracheal intubation and all its potential complications (pneumonia, difficulty weaning, tracheostomy, prolonged hospitalization). ${ }^{3}$

\section{Setting: RICU \& IICU}

\section{Methods}

We enrolled 10 consecutive patients admitted at IICUs/RICU, diagnosed with COPD in ARF, age 18-80 y.o.; $\mathrm{BMI}<35$, arterial $\mathrm{CO}_{2}$ $>20 \%$ from basal value; arterial $\mathrm{pH}>7.15 \&<7.30$; respiratory rate $>30$ breaths/min, paradoxical abdominal movements. On admission SOFA, APACHEII \& SAPSII scores were captured.

We focused on three primary end points:

1) Reduction of arterial $\mathrm{CO}_{2}$, increasing of arterial $\mathrm{pH}$ and reduction of RR
2) Prevention of endotracheal intubation

3) Providing early support to patient weaning ${ }^{4,5}$

\section{Results}

Eight of ten patients avoided E.T.I. and were easily weaned from NIMV with arterial $\mathrm{CO}_{2}$ levels returning to basal value after $48 \mathrm{~h}$ of treatment. One subject was not responsive to NIMV and was treated with invasive ventilation. One subject was removed from treatment for hypersensitivity to heparin and bleeding from arterial catheter.

\section{Conclusion}

This study supports the use of non-invasive mechanical ventilation in combination with ECCO2R in hypercapnic respiratory failure due to COPD. ${ }^{6}$ In addition we suggest assessing the effectiveness of noninvasive ventilation to reduce potential complications and time of hospitalization in this patient population.

\section{References}

1. Chandra D, Stamm JA, Taylor B, et al. Outcomes of noninvasive ventilation for acute exacerbations of chronic obstructive pulmonary disease in the United States, 1998-2008. Am J Respir Crit Care Med. 2012;185(2):152-159.

2. Del Sorbo L, Pisani L, Filippini C, et al. Extracorporeal $\mathrm{Co}_{2}$ removal in hypercapnic patients at risk of noninvasive ventilation failure: a matched cohort study with historical control. Crit Care Med. 2015;43(1):120-127.

3. Quinnell TG, Pilsworth S, Shneerson JM, Smith IE. Prolonged invasive ventilation following acute ventilatory failure in COPD: weaning results,
Submit your Article | www.ologypress.com/submit-article

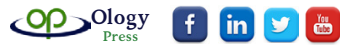


survival, and the role of noninvasive ventilation. Chest. 2006;129(1):133139.

4. Burki NK, Mani RK, Herth FJF, et al. A novel extracorporeal CO(2) removal system: results of a pilot study of hypercapnic respiratory failure in patients with COPD. Chest. 2013;143(3):678-686.

5. Lewandowski K. Extracorporeal membrane oxygenation for severe acute respiratory failure. Crit Care. 2000;4(3):156-168.

6. Hill JD, O'Brien TG, Murray JJ, et al. Prolonged extracorporeal oxygenation for acute post-traumatic respiratory failure (shock-lung syndrome). Use of the Bramson membrane lung. N Engl J Med. 1972;286(12):629-634. 